\title{
doispontos:
}

\section{A "física experimental da alma" na Popularphilosophie: a analogia entre física newtoniana e psicologia wolffiana}

\author{
The "experimental physics of the soul" in the Popularphilosophie: an analogy between newtonian \\ physics and wolffian psychology.
}

\author{
Mario Spezzapria \\ Professor Adjunto de Filosofia da Universidade Federal do Mato Grosso - UFMT \\ mariospezzapria@yahoo.it
}

\begin{abstract}
Resumo: Christian Wolff (1679-1754) foi o primeiro filósofo que separou a doutrina da alma em duas partes: a "psychologia empírica" e a"psychologia rationalis". Ele deu certa ênfase sobretudo à primeira parte, mais nova e original, que tratava daqueles conhecimentos das faculdades da alma derivados da observação dos dados da experiência, ao passo que a segunda parte tratava das reflexões (derivadas de uma longa tradição metafísica) sobre a essência e a imortalidade da alma. Em certa medida, a psicologia empírica procedia segundo um método análogo àquele da física newtoniana e da astronomia kepleriana, baseado num círculo virtuoso entre fatos observados e reflexões teóricas. A importância desta concepção de "experiência" estaria na origem do rápido abandono, nas traduções alemães e franceses (a "psychologia empírica" foi originariamente publicada em latim), do adjetivo "empírico" em favor das expressões Erfahrungspsychologie, Experimental-Seelenlehre e Psychologie expérimentale. A astronomia e a física newtoniana fascinavam pela capacidade heurística de produzir novos conhecimentos. Tratava-se, então, de deslocar este método da natureza física para o conhecimento do homem. Assim, na segunda metade do século XVIII, assistese na Alemanha aos desenvolvimentos de uma "física da alma" (Physik der Seele), como definida por Sulzer e Herder. Autores como Johann Krüger, Karl Moritz, Ernst Platner, Marcus Hertz trabalham em projetos de aprofundamento desta pesquisa sobre os "fatos" da alma, dando a estas reflexões psicológicas a consistência de uma antropologia.
\end{abstract}

Palavras-chave: psicologia empírica; experiência; física da alma; antropologia.

\begin{abstract}
Christian Wolff (1679-1754) was the first philosopher who separated the doctrine of the soul in two parts: "psychologia empirica" and "psychologia rationalis". He emphasized above all the first newer and more original part, that dealt with those knowledges of the faculties of the soul, derived from the observation of the data from experience, whilst the second part dealt with reflexions (derived from a long metaphysical tradition) on the essence and immortality of the soul. To some extent, the empirical psychology was meant to follow a method like the one of the Newtonians physics and the Keplerian astronomy, based on a virtuous circle between the observed facts and the theorical reflexions. The importance of such a conception of experience would be at the origin of the quick abandonment in the German and French translations (the "psychologia empirica" was originally published in Latin) of the adjective "empirical" in favour of the expressions Erfahrungspsychologie, Experimental-Seelenlehre e Psychologie expérimentale. The Newtonian astronomy and physics fascinated for the heuristic capacity to produce new knowledge. It was then necessary to transfer this method applied to the physical nature to the knowledge of man. In the second half of the 18th Century, we observe in Germany to the developments of a "Physic of the Soul" (Physik der Seele), as it was defined by Sulzer and Herder. Authors like Johann Krüger, Karl Moritz, Ernst Platner, Marcus Hertz also worked in projects developing this research on the "facts" of the soul and giving to these psychological reflexions the consistency of an anthropology.
\end{abstract}

Keywords: empirical psychology; experience; physic of the soul; anthropology. 


\section{Wolff e a articulação entre psicologia empírica e racional}

Como é notório, Christian Wolff (1679-1754) foi o primeiro filósofo que, na sua organização sistemática da filosofia, separou a doutrina da alma em duas grandes partes: psicologia racional e psicologia empírica. A psicologia racional - dito de forma muito geral - tratava a priori de temas como a essência e o destino da alma após a morte (assuntos pertencentes à formulação tradicional da metafísica), contando sobretudo com o rigor dedutivo dos raciocínios. A psicologia empírica, ao contrário, se ocupava das observações e reflexões resultantes em grande medida de um processo de introspeção, e era, portanto, considerada como um conhecimento do homem "a posteriori", fundado em experiências subjetivas. Tais experiências, sendo comuns a todos os homens, poderiam ser reconhecidas e compartilhadas por todos os sujeitos que

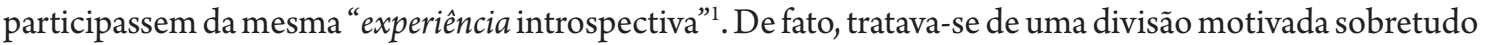
por exigências expositivas e sistemáticas, não apenas pelo fato de que a psicologia racional e a empírica representavam dois aspectos diferentes do mesmo saber (o conhecimento da alma), mas também pelo fato de que considerações "a priori" e "a posteriori” encontravam-se efetivamente nas "duas" psicologias. De modo geral, um dos motivos mais originais da filosofia wolffiana era a ideia de que seria impossível distinguir completamente no interior do nosso conhecer a atividade de mera observação e o momento especulativoreflexivo, os quais "convivem” em uma contínua e mútua síntese e numa dinâmica de inter-relação.

Não obstante a procura deste equilíbrio de síntese, não há dúvida de que a parte mais nova e original da doutrina da alma wolffiana, em comparação à tradição filosófica, era a psicologia empírica. A esta, o filósofo de Breslau dedicou muito mais espaço do que à “irmã”, isto é, à psicologia racional. Ademais, de um ponto de vista sistemático-expositivo, a psicologia empírica tinha sim alguma prioridade sobre a racional (como também sobre outras partes do sistema: lógica, teologia, etc.), porém não pela relevância dos dados derivados da experiência a respeito da elaboração racional, mas em razão da produção do maior grau de conhecimento e consciência sobre a natureza das nossas faculdades da alma (pensamento, imaginação, desejo, memória). Por isso, a reflexão psicológica empírica estava no fundamento de qualquer outro tipo de conhecimento ${ }^{2}$.

A importância e a novidade da psicologia empírica foi imediatamente entendida pelos numerosos leitores e seguidores de Wolff, e por toda a segunda metade do século XVIII se assistirá na Alemanha, sobretudo no âmbito da assim chamada filosofia popular, a várias tentativas de reelaboração e aprofundamento dos temas ali contidos, em detrimento das questões "típicas” da psicologia racional.

Estas questões, embora ainda fossem temas relevantes nos debates da época (como no caso da ampla discussão sobre o destino da alma após a morte entre Moses Mendelssohn, Herder e Thomas Abbt, ou do problema da harmonia preestabelecida entre alma e corpo, um legado leibniziano), parecem perder importância de um ponto de vista sistemático, e a psicologia racional, enquanto disciplina autônoma, é aos poucos relegada à margem das reflexões filosóficas e antropológicas contemporâneas sobre a alma.

\section{A psicologia como física experimental}

Parece que o primeiro a utilizar a expressão "física experimental da alma" (physique expérimentale de l'âme) no contexto da psicologia foi o filosofo francês Jean Baptiste Le Ronde D'Alembert, no famoso Discurso preliminar da Enciclopédia de 1751. A expressão foi utilizada logo depois de um longo elogio a Newton, considerado, junto com Kepler, o verdadeiro gênio da filosofia natural. O grande mérito dos dois, respectivamente nos campos da física e da astronomia, consistiria na ênfase dada às "experiências" e "observações", em detrimento das "conjecturas e hipóteses vagas", numa nova atitude que teria possibilitado a extensão dos conhecimentos da natureza física. $\mathrm{O}$ afastamento de uma atitude especulativa e vagamente abstrata em favor de uma maior aderência ao que era observável e concretamente experimentável, teria se traduzido em um aumento do conhecimento. No que diz respeito 
à metafísica, ao contrário, D’Alembert salientava o fato de que Newton, embora certamente tivesse se ocupado dela, teria preferido não enfrentar este tema nos seus ensaios mais famosos:

\begin{abstract}
Assim, como nesse ponto [na metafísica, Newton] não causou nenhuma revolução, abster-nos-emos de considerá-lo sob esse aspecto. O que Newton não ousara ou talvez não tivesse podido fazer [n'avait osé, ou n'aurait peut-être pu faire], Locke empreendeu e executou com êxito. Pode-se dizer que ele criou a Metafísica mais ou menos como Newton criara a Física. Concebeu que as abstrações e as questões ridículas que haviam sido agitadas até então e que haviam sido como que a substância da Filosofia, constituíam a parte que sobretudo era preciso proscrever. Procurou, nessas abstrações e no abuso dos signos, as causas principais de nossos erros, e encontrou-as. Para conhecer nossa alma, suas ideias e suas afecções, não estudou os livros, porque não poderiam instruí-lo adequadamente, contentou-se em mergulhar profundamente em si mesmo, e após ter, por assim dizer, contemplado a si mesmo longamente, apenas apresentou aos homens, em seu Ensaio sobre o entendimento humano, o espelho em que se vira. Numa palavra, reduziu a Metafísica ao que ela deve ser de fato, uma Física experimental da alma, espécie de Física muito diferente daquela dos corpos, não somente por seu objeto como também pela maneira de considerá-lo 3 .
\end{abstract}

Nesta reconstrução da história moderna da redução da metafisica à "física experimental da alma", D’Alembert atribui ao filósofo empirista britânico John Locke o mérito de ter operado como Newton e Kepler haviam feito no âmbito dos fenômenos físicos. Curioso é o fato de que a expressão de D’Alembert "ce que Newton n'avait osé, ou n'aurait peut-être pu faire, Locke l'entreprit et l'exécuta avec succès" ecoa de maneira bastante fiel a um trecho de uma tradução-comentário anônima, em francês, da psicologia empírica wolffiana, publicada em 1745 com o título Psychologie, ou Traité sur l'âme, contenant les connaissances que nous en donne l'expérience ${ }^{4}$. Na introdução, o autor anônimo escrevia assim:

Redevables de mille découvertes à l'expérience, il convenoit en quelque façon, qu'après l'avoir employée si utilement pour surprendre une partie des secrets de la Nature, nous nous en servissions pour épier e pour pénétrer ceux de l'Ame; ce que l'on n'auroit presque pû penser, M. W. [Wolff] l'a tenté, cette même expérience, ce grand instrument qui demande des yeux si perçant, et des mains si habiles, il a osé l'appliquer a l'Ame même, il l'a soumise comme le reste de la Nature à un examen, et l'a assujettie à des loix: entrons à la suite dans ce labyrinthe, et tâchons de saisir le fil qu'il nous présente pour y marchers.

Como se vê, não só há uma correspondência bastante precisa entre os termos utilizados por D’Alembert e as palavras do anônimo autor do Traité sur l'âme (Locke ousa fazer o que Newton não teria sabido ou podido fazer; Wolff ousa aplicar a experiência ao domínio da alma), mas também o contexto no qual elas são pronunciadas é bastante parecido: trata-se de um paralelo entre a práxis das investigações sobre a natureza e as descobertas que podem ser feitas em relação ao mundo interior do homem, ainda bastante desconhecido. Na introdução do Traité sur l'âme, diferentemente do que acontecia em D’Alembert,

\title{
${ }^{3}$ DIDEROT, D; D'ALEMBERT, 2015, p. 177.
}

${ }^{4} \mathrm{Na}$ obra Médicine de l'esprit, o médico francês Antoine Le Camus (1722-1772), depois de citar amplos excertos do Traité sur l'âme, afirma: «M. l'Abbé Allaire, qui a analisé l'ouvrage de Wolf, ajoute à ces exemples celui de M. Malet de l'Académie Françoise [etc. etc.] 》. LE CAMUS, 1769, p. 299. O anônimo o autor da tradução resumida da psicologia empírica seria, portanto, François Allaire (Saint-Brieuc? - 1776?), abade de Huiron e Bom-Repos e preceptor do duca de Chartres Luis-Philippe d'Orleans. Esta informação corresponde àquilo que é afirmado no Catalogue d'une très belle et nombreuse collection de livres: "496 Psychologie ou traité sur l’àme, par Wolf. Amst., 1745, in-12. Cette ouvrage n'est que le résumé du grand travail de Wolf, su le méme matière; il a pour auteur l'abbé Allaire (Note de M. Massau)". ANONIMO, 1848, p. 27. Frequentemente o Traité sur l'àme é atribuído ao wolffiano Jean Des Champ, mas esta atribuição pode ser desmentida pelas palavras que o próprio Des Champ usa na sua tradução da psicologia empírica, incluída no Cours abrégé de la philosophie wolffienne, em que ele se pergunta quem poderia ser o anônimo autor da obra: «Dans le temps que j'écrivois ceci, il m’est tombé entre les mains un nouveaux livre intitulé Psychologie, ou Traité sur l'âme, contentent les connaissances que nous en donne l'expérience, par Mr. Wolff, imprimé à Amsterdam, chez Pierre Mortier, en 1745. A la vue de ce titre, et surtout à la première lecture de l'ouvrage même, j’ai balancé si je publierois ce-lui-ci, vu qu'un autre m’avoit prévenue d'une manière si avantageuse pour le public. Effectivement, l'anonyme qui vient de nous donner cette excellente production, mérite à plus d'un égard nos remercîments et nos éloges; car son livre est écrit avec tout l'agrément possible, avec beaucoup d'ordre et de jugement, et d'une manière très propre à donner une grande idée de son habileté et de son savoir. J'ai soupçonné plus d'une fois en le lisant, que cet auteur est un académicien, ou tout au moins un orateur de profession, tant il a su répandre de fleurs et de figures de rhétorique dans son stile, et donner carrière a sa brillante imagination. D’autre fois je l'ai pris pour un homme de guerre, et entre autres, en conséquence de l'exemple particulier qu'il cite à la page $147 \mathrm{du}$ siège de Prague de l'an 1742 et dont il parle comme témoin oculaire ...» (DES CHAMPS, 1747, p. XVII-XIX).

${ }^{5}$ WOLFF, 1745, p. 34. Grifo meu. 
salientava-se uma afinidade metodológica entre a física newtoniana e a astronomia kepleriana com a psicologia empírica wolffiana (note-se que, em francês, a expressão "psicologia empírica" é traduzida como "psychologie expérimental", apesar da disponibilidade do adjetivo empirique):

C'est la Psychologie expérimental, nous dit-il, qui établit \& confirme ce que nous avons découvert par la Psychologie raisonnée; c'est elle, qui lui fournit ses principes; à peu près comme nous voions dans la Physique \& l'Astronomie un habile Observateur tirer successivement de ses Observations, de quoi établir sa Théorie, \& de sa Théorie de quoi apuier ses observations, \& par ce double secours s'élever à de nouvelles connoissances, qui lui auroient échappé sans ce concert \& cette intelligence ${ }^{6}$.

Há boas probabilidades de que D’Alembert, ao apresentar o conceito de uma "física experimental da alma”, estivesse se referindo a este mesmo texto. Se for assim (como acredito), a posição do filósofo francês pareceria ter um caráter algo "conservador", sobretudo levando em conta o momento histórico, já que, no período, o pensamento wolffiano não só gozava de enorme sucesso na Alemanha (era objeto de grande consideração nos ambientes da corte real de Berlim, na qual era tomado como suprassumo do pensamento filosófico alemão), mas era também seguido com grande interesse em outros países europeus (na Itália, por exemplo). Na própria França, Wolff era bastante discutido e traduzido (entre as obras de divulgação da filosofia wolffiana, eram particularmente famosas as Institutions physiques da marquesa Émilie Du Châtelet), e não poucos verbetes da Encyclopédie foram redigidos - na maioria dos casos de forma apócrifa - a partir de textos de Wolff ou de wolffianos, embora esta origem não fosse declarada e permanecesse oculta ${ }^{7}$. Sob esta luz, é legitimo ficar surpreso com o silêncio de D’Alembert acerca de Wolff e da sua escolha de detectar na filosofia lockiana a presença de uma psicologia "experimental". Pode-se, talvez, ler em filigrana, "nas entrelinhas" das palavras de D'Alembert, uma crítica à maneira como Wolff tinha pensado a psicologia, ou mesmo uma denúncia implícita da inconsistência dessa maneira?

\section{Sulzer e a física experimental da alma}

Alguns anos depois da publicação do Discurso preliminar de D’Alembert, a expressão "física experimental da alma” é recuperada pelo teólogo e filosofo suíço Johann George Sulzer (1720-1779) na segunda edição da sua obra Kurzer Begriff aller Wissenschaften (1759), um compêndio das "ciências filosóficas" da época. Falando sobre a psicologia, Sulzer escreve:

\footnotetext{
Die Psychologie ist also die [Wissenschaft der menschlichen Seele]. Sie erforscht ihre Natur, ihr Wesen, ihre Kräfte und Vermögen, ihre Eigenschaften und die Veränderungen, welche sich natürlicher Weise zutragen können. Sie bestehet aus zwei Haupteilen, welche Wolf durch die Namen Psychologia empirica und Psychologia rationalis von einender unterschieden hat. Der erste Teil (Psychologia empirica) enthält eine deutliche und genaue Beschreibung alles dessen, was uns von der Seele durch die Erfahrung bekannt ist. [...] Man verfährt hiebei, wie in der Physik mit den körperlichen Dingen, welche man durch Erfahrungen und Versuche kennen lernt. Man könnte also diesen Teil der Psychologie die Experimentalphysik der Seele nennen".
}

Ao reconduzir a Experimentalphysik der Seele à psicologia empírica wolffiana, Sulzer especificava claramente a afinidade desta com a física natural. Tem-se a impressão de que, desta maneira, ele estaria "atribuindo

\footnotetext{
${ }^{6}$ WOLFF, 1745 , p. 23. Grifo meu. A analogia metodológica entre a física newtoniana e a psicologia wolffiana, como filosofia experimental, na qual o tradutor insiste no avant-propôs do Traité sur l'âme, corresponde àquilo que encontramos no Discurso Preliminar, quando Wolff recorre a exemplos de Newton para delinear a relação entre conhecimento histórico e filosófico.

${ }^{7}$ A questão da presença do pensamento wolffiano na Encyclopédie é um tema ainda pouco estudado. Permito-me mencionar meu artigo "A presença da filosofia leibniziana e wolffiana na Encyclopédie" (AA. VV, 2019, p. 87-92).

${ }^{8}$ SULZER, 1759, p. 156-157. Grifo meu. A primeira edição da obra, de 1745, não contém as partes sobre a psicologia. Não é, todavia, a primeira vez que Sulzer usa a expressão "física da alma". Com efeito, já em 1754, no ensaio Von dem Bewusstsein, o filosofo suíço lamentava a ausência na filosofia de "uma parte muito essencial e consideravelmente difícil, quer dizer, a teoria metafísica do homem ou o que alguns filósofos denominam de física da alma [Physik der Seele].” SULZER, 1773, p. 199. Stephanie Buchenau monstra a concepção sulzeriana de filosofia como física da alma derive da analogia com a medicina. BUCHENAU, 2019, p. 13-42. Disponível em: <https://www.editoraclandestina.org/>
} 
novamente" a "verdadeira" paternidade da aplicação dos métodos da ciência dos corpos (física) à doutrina do conhecimento da alma (psicologia), retomando as considerações a este respeito que estavam presentes na psicologia empírica wolffiana e que, como se vê, são ressaltadas na tradução/comentário francesa de 1745. Vale lembrar que a Encyclopédie tinha como público "natural" principalmente os franceses, ao passo que a obra de Sulzer era essencialmente endereçada aos leitores de língua alemã. Para o público alemão dos Gelehrte dos anos 50, Wolff era um filósofo de grande fama, que tinha conseguido reordenar com eficácia os grandes temas da filosofia leibniziana, inserindo nela novas e originais reflexões. Era sobretudo a partir das novidades do filósofo de Breslau que deveriam ser desenvolvidas as linhas principais da nova filosofia alemã. E é por esta razão e desta perspectiva que Sulzer, na segunda edição da Kurzer Begriff aller Wissenschaften, indicava as direções que, na sua opinião, os desdobramentos (a expressão que ele utiliza é Erweiterungen, "extensões") da psicologia empírico-experimental deveriam ter seguido.

\section{Física newtoniana e psicologia wolffiana: tensão entre a priori/a posteriori.}

Antes de passar a considerar os desenvolvimentos para o futuro da psicologia empírica almejados por Sulzer, vale a pena fazer algumas considerações sobre o significado teórico da analogia entre a física newtoniana e a psicologia empírico-experimental.

A própria expressão "física da alma" (Physik der Seele) é muito interessante. Aos olhos dos leitores da época devia aparecer bem claramente o oximoro que a constitui. Desde os tempos de Aristóteles, as reflexões sobre a natureza da alma eram enquadradas no interior da meta-física, à qual elas pertenciam, em primeiro lugar, por causa da essência imaterial do objeto em questão. Os discursos sobre a natureza dos corpos eram próprios do domínio da física; aqueles sobre a natureza dos "objetos imateriais", não corpóreos (como a "alma"), eram colocados na esfera da metafísica. O âmbito da metafísica incluía tradicionalmente também outros entes (ser e deus; ontologia e teologia) desprovidos de consistência corpóreo-material (portanto, "espirituais"). De toda forma, podia-se dizer que, pelo menos no que diz respeito à natureza do homem, a divisão entre física e metafísica correspondia àquela entre corpo e alma. É claro que tais entes "imateriais" pertencentes à metafísica tinham um estatuto problemático: eles certamente faziam parte do nosso conjunto de experiências interiores, mas quem podia garantir que estas não eram meras ilusões, sonhos, quimeras, e não realidade? No caso da alma, no âmbito psicológico a evidência da sua existência era atribuída à auto-percepção de si mesmo. Agora, com a expressão "física da alma" se propunha que o próprio critério de evidência, implementado nas observações e experiências dos corpos físico-naturais feitas por físicos e astrônomos, pudesse ser aplicado às observações e experiências (entendidas, portanto, como "dados de fato") do nosso mundo interior. Dito de outra forma: propunha-se a adequação daquela metodologia tão bem-sucedida na ampliação dos conhecimentos do mundo físico externo ao homem ao mundo interior, cujos fenômenos pareciam em grande medida ainda por descobrir 9 .

O oximoro "física da alma" abalava e colocava em questão, portanto, a distinção clara e "canônica" entre uma ciência dos corpos e dos seus movimentos (física) e um conhecimento dos entes "espirituais", e era um sintoma revelador da tendência da Alemanha da época reconsiderar o domínio da psicologia, dando preferência a uma definição não baseada na natureza (corpórea o espiritual) do objeto em questão, mas fundada na metodologia experimental (ou experiencial). Tal processo de reconsideração e recolocação do domínio da psicologia é atestado simultaneamente por dois fenômenos: 1) a tendência à uma valorização do momento empírico-experimental em detrimento da argumentação "racional"; 2) a tradução da expressão latina "psicologia empírica" por psychologie expérimentale em francês, e por Erfahrungs-Seelenlehre (ou

\footnotetext{
${ }^{9}$ É preciso dizer que este é um traço tipicamente iluminista: a importância das descobertas e do aumento progressivo dos conhecimentos; "iluminar" mundos obscuros. Por outro lado, os românticos percebem o paradoxo desta pretensão: o homem tem algumas "obscuridades" no fundo da própria alma destinadas a permanecerem obscuras e que "funcionam" apenas na permanência da própria incompreensibilidade essencial e irreduzível.
} 
Experimental-Seelenlehre) em alemão, embora as duas línguas tenham à disposição no próprio vocabulário os adjetivos empirique e empirisch.

De modo geral, observa-se que, nas reflexões dos continuadores de Wolff, a ideia de uma "metafisica" enquanto categoria capaz de dar razão aos fenômenos e às experiências do objeto-alma tende a perder importância, ao passo que se acreditava encontrar no paradigma experimental da física um modus operandi, no qual as considerações das experiências a posteriori e as reflexões analítico-dedutivas a priori eram harmoniosamente conciliadas em um ciclo virtuoso, capaz de fornecer uma real extensão dos conhecimentos.

Tratava-se de uma dissolução da ideia da metafisica que já estava presente "in nuce" na mesma concepção de connubium rationis et experientiae, que - como acenamos - estava no fundo de grande parte da estruturação do sistema wolffiano. É, portanto, na complementariedade e na inter-relação constitutiva e real dos dois momentos a priori e a posteriori, já presentes no pensamento wolffiano como um dos traços mais característicos, que são fundados os desenvolvimentos dos continuadores do ensino do "mestre dos alemães" (como Wolff era chamado).

\section{Sulzer e os rumos da física da alma na Popularphilosophie}

Tendo chegado até aqui, podemos agora voltar aos desenvolvimentos que, em 1759, Sulzer desejava e indicava para a tarefa de reflexão empírico-experimental sobre a alma inaugurada por Wolff. De certa forma, Sulzer nos fornece um resumo sintético das principais formas em que a física da alma estava efetivamente se desdobrando no âmbito da Popularphilosophie alemã.

Resumindo sucintamente, segundo Sulzer tratava-se, em primeiro lugar, de prestar a maior atenção possível aos "objetos" obscuros da alma, que "atingida" por milhares de estímulos e percepções, é sede de uma quantidade enorme de sensações. Wolff havia descrito muito bem os efeitos positivos dos pensamentos e juízos claros no nosso conhecimento intelectual (esclarecer as razões das coisas: tratava-se, neste caso, de um elemento "racionalista" e tipicamente "iluminado" do pensamento wolffiano). Fazer distinções claras era a principal tarefa do conhecimento. Mas Leibniz já evidenciara a existência no fundo obscuro da alma (Grund der Seele) de petites perceptions, as quais, mesmo que não fossem trazidas para nossa consciência, atuavam, todavia, fortemente no nosso ânimo. Wolff prossegue declarando a importância de esclarecer a conduta da alma (das Betragen der Seele) no caso do conhecimento obscuro, assim como em presença dos juízos rápidos (schellen Urteilen), que seguem o conhecimento intuitivo (Cf. SULZER, 1759, p. 158159). Vê-se como se trata de um ponto sobre o qual, por exemplo, o filósofo Baumgarten estava refletindo naqueles anos, na sua obra metafisica e estética. Tratava-se, em segundo lugar, tentar explicar os "casos extraordinários" que não se deixavam enquadrar nas características conhecidas da alma (Cf. SULZER, 1759, p. 159-160). Este ponto reenvia aos trabalhos de médicos e filósofos da época, como Johann Krüger, autor da Versuch einer Experimental-Seelenlehre, (KRÜGER, 1756; STIENING, 2016, p. 119-145) e Karl Philipp Moritz, os quais perceberam a falta de um trabalho de observação detalhada dos "fatos" da alma (sonhos, traumas infantis, distúrbios da personalidade, premonições), a partir das quais, em um segundo momento seria possível construir uma psicologia fundada não em reflexões abstratas, mas na "vida real" dos indivíduos. Em particular Karl Moritz fundara em Berlim, com o apoio dos intelectuais esclarecidos berlinenses, uma revista inovadora, a Magazin zur Erfahrungs-Seelenkunde $(1783-1793)^{10}$, com o intuito de dar espaço às narrativas dos leitores. Essas narrativas serviriam como instrumento para obter uma quantidade adequada e suficiente de dados empíricos, sobre os quais poderia ser construída uma nova psicologia não dogmática. Por fim, segundo Sulzer o terceiro e último desdobramento da "física da alma" consistia na elaboração de uma reflexão ulterior a propósito da harmonia entre os estados do corpo e da alma e das suas relações (Cf. SULZER, 1759, p. 160). Esse desdobramento remete aos esforços feitos pela assim chamada "medicina antropológica", representada por importantes personagens, como Ernst Platner 
e Marcus Hertz. Assim, vemos como, na segunda metade do século XVIII, assumindo como consolidado o fundo teórico e metodológico indicado por Wolff, parte importante da reflexão teórica da filosofia popular alemã tentava edificar uma nova psicologia voltada para a descoberta de novos conteúdos experimentais e experienciais, ou seja, sobre as experiências narráveis da própria interioridade. 


\section{Referências bibliográficas:}

BUCHENAU, S. Entre medicina e filosofia. Sulzer - Herder - Kant - Maimon. Tradução de André Aureliano Fernandes, Márcio Suzuki e Oliver Tolle. São Paulo: Editora Clandestina, 2019.

[ANONIMO]. Catalogue d'une très belle et nombreuse collection de livres de theologie, de Jurisprudence, de Sciences et Arts, de Littérature, de Géographie, d'Histoire, de Bibliographie, de Biographie, etc. Bruxelles: Fevrier 1848.

DES CHAMPS, J. Cours abrégé de la philosophie wolffienne, en forme de lettres. Tome seconde. Première partie. Amsterdam \& Leipzig: Arkstee \& Merkus, 1747.

DIDEROT, D; D 'ALEMBERT, J. Enciclopédia, ou Dicionário razoado das ciências, das artes e dos ofícios. Volume 1 Discurso preliminar e outros textos. Organização Pedro Paulo Pimenta e Maria das Graças de Souza Tradução Fúlvia Moretto e Maria das Graças de Souza. São Paulo: Editora UNESP, 2015.

KRÜGER, J. G. Versuch einer Experimental-Seelenlehre. Halle, Helmstädt: Hemmerde, 1756.

LE CAMUS, A. Médicine de l'esprit. Ganeau: Paris, 1769.

MORITZ, K. P. Revista de psicologia empírica e A miséria humana. Apresentação de Mario Spezzapria. Introdução, tradução e notas de Oliver Tolle. Departamento de Filosofia da USP: Cadernos de Tradução, 2020.

SPEZZAPRIA, M. “A presença da filosofia leibniziana e wolffiana na Encyclopédie”. In: AA. VV. Filosofia do século XVII. Organização Cesar Augusto Battisti. São Paulo: Anpof, 2019, pp. 87-92.

STIENING, G. "Zwischen System und Experiment. Johann Gottlob Krügers Versuch einer ExperimentalSeelenlehre”. Quaestio. Annuario di Storia della Metafisica, vol. 16, 2016, a cura di Enrico Pasini e Paola Rumore, pp. 119-145.

SULZERJ. G. “Kurzer Begriff aller Wissenschaften und andern Theile der Gelehrsamkeit”, 2. überarbeitete Auflage. Frankfurt, Leipzig, 1759.

SULZER, J. G. Von dem Bewusstsein. In: . Vermischte Philosophische Schriften, Leipzig, 1773.

WOLLF, C. Discursus Praeliminaris de filosofia in genere. Einleitende Abhandlung über Philosophie im Allgemeinen. Historish-kritische Ausgabe. Übersetzt, eingeleitet und herausgegeben von Günther Gawlich und Lothar Kreimendahl. Stuttgart-Bad Cannstatt: frommann holzboog, 1996.

.Discours préliminaire sur la philosophie en général. Traduction sous la direction de Th. Arnaud, W. Feuerhahn, J.-F. Goubet et J.-M. Rohrbasser. Paris: Vrin, 2006.

Clandestina, 2018.

. Psicologia empírica. Prefácio e prolegômenos. Tradução de Márcio Suzuki. São Paulo:

. Psychologie ou traité sur l'âme, contenant les connaissances que nous en donne l'expérience. Amsterdã: Pierre Mortier, 1745.

Recebido em 27 de julho de 2020. Aceito em 06 de agosto de 2020. 